\title{
Glosa
}

\section{especulação bastarda ao redor da água}

\section{LEOPOLDO WAIZBORT}

Para José Carlos Bruni, em testemunho de amizade, admiração e agradecimento, na ocasião de seu sexagésimo aniversário

"os mares, os oceanos, os rios, os lagos, os regatos, os riachos, as torrentes, as chuvas, as fontes, as nascentes, as praias, as quedas d'água,

as cascatas, o gelo, o orvalho, [...] as águas claras, as águas correntes, as águas primaveris, as águas profundas, as águas dormentes, as águas mortas, as águas compostas, as águas doces, as águas violentas, as lágrimas."

(Bruni, 1993, p. 59)

"y bajo el agua puso oscuridad, y la ciencia humana no ve más allá de ese punto."

(Borges, 1997, p. 590)

"Só como náufrago naveguei pelo mar com felicidade"

(Zenão de Kition apud Blumenberg, 1997, p. 15)

RESUMO: Debruço-me sobre um artigo anteriormente publicado em Tempo social, de autoria de José Carlos Bruni, na tentativa de "compreender a água enquanto água" e as implicações de tal empresa.

PALAVRAS-CHAVE: água.

Tales de Mileto José Carlos Bruni

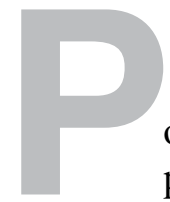

ara um habitante do arquipélago grego, como Tales, bastava ir até a orla para saber que "tudo é água". Para nós outros, contudo, a afirmação conjuga obscuridade, provocação e, até mesmo, algo de despeito frente a um pensamento que se quer sempre e cada vez mais senhor. "Água fresca faz olhos claros" (Feuerbach apud Bruni, 1993, p. 58), mas a frase de Tales parece antes ofuscar e mesmo cegar os olhos modernos, pois o seu gênero serve, para a mente classificatória e explanatória, como confusão e indiferenciação.
Leopoldo Waizbort é aluno de José Carlos Bruni 
${ }^{1}$ Para os mais eruditos, a fonte é Diógenes Laércio (Diels, A1): Arkhèn dè tôn pánton hýdor hypestésato: Ele situava a água na origem de tudo (cf. Legrand, 1991, p. 27).

2 T. S. Eliot, Death by water. Morte pela água. Flebas, o fenício, há quinze dias morto,/ Esqueceu o grito da gaivota, o inflar do mar profundo/ E os lucros e perdas./ Uma corrente submarina murmurando/ Seus ossos recolheu. Imer-gindo e aflorando/ Flebas ultrapassou velhice e mocidade/ E na voragem se perdeu./ Gentio ou judeu/ Ó tu que a roda giras e a barlavento olhas/ Pensa em Flebas/ Um dia teu igual em estatura e linhagem. A Terra Gasta - IV. 19211922. (Eliot et alii, 1992, p. 47). (N. E.).
A frase nunca foi um oráculo; hoje ela irrita. Entretanto, nem todos dão-se ao trabalho de sensibilizar-se por essa irritação. Mas, como nem sempre esse é o caso, às vezes ocorre a alguém debruçar-se novamente sobre a água; ocasionalmente, até, arriscar um mergulho. É o caso daquele que se propõe a "compreender a água enquanto água" (Bruni, 1993, p. 54); que se vê aturdido pela frase de Tales, "pela sua radical brevidade, pela brutal distância que estabelece com o senso comum, pelo mistério e beleza que a envolvem na sua pureza e no seu isolamento" (Bruni, 1993, p. 54)1.

Trata-se, é preciso dizê-lo, de um espírito aventureiro, inquieto, por mais que sua forma exterior esconda tal verdade interior. Ele não tem medo d'água!

\section{É doce morrer no mar \\ nas ondas verdes do mar}

Mesmo se náufrago, mesmo se tragado pelas vagas do mar alto, dele se poderia com justeza dizer:

Phlebas the Phoenician, a fortnight dead,

Forgot the cry of gulls,

And the deep sea swell And the profit and loss.

A current under sea

Picked his bones in whispers. As he rose and fell

He passed the stages of his age and youth

Entering the whirlpool.

\section{Gentile or Jew}

O you who turn the wheel and look to windward, Consider Phlebas, who was once handsome and tall as $\mathrm{you}^{2}$.

"Tudo é água" é uma metáfora absoluta e explosiva, um caso que se situa algo além dos limites da conceptualidade clara e distinta. A água é polimorfa, sem forma; sem cor, de todas as cores. O predicado opera um "acoplamento do heterogêneo" (Blumenberg, 1997, p. 102), logrando, assim, dizer algo que de outro modo permaneceria indizível. Crê-se, pois, que se deve falar daquilo que não se pode falar.

Isto significa que tocamos os limites da conceptualidade, sem que com isso tenhamos de renunciar ao conhecimento. "A metafórica já não é vista de preferência como esfera principal de concepções teóricas ainda hesitantes, como terreno preliminar de formação de conceitos, como auxílio na situação ainda não consolidada de linguagens especializadas, mas sim como um modo eficiente e autêntico da apreensão de nexos, que não se pode limitar ao núcleo restrito da 'metáfora absoluta'. Esta última era também definida a princípio pela sua indisponibilidade para ser 'substituída por predicados objetivos' no mesmo plano lingüístico. Poderia dizer-se que o ponto de vista se inverteu: já não se aplica só, antes de mais, à constituição de conceptualidade, mas também às ligações retrospectivas ao 
mundo da vida, enquanto apoio constante - embora impossível de manter constantemente presente - da motivação de toda a teoria. Já que temos de concordar que não podemos esperar da ciência $a$ verdade, então queremos saber, pelo menos, porque quisemos saber algo cujo saber está associado à desilusão. Nesse sentido, as metáforas são fósseis que servem de guia de um estrato arcaico do processo da curiosidade teórica, que não tem por isso de ser anacrônico, pois não existe retrocesso à plenitude das suas estimulações e expectativas de verdade" (Blumenberg, 1997, p. 87).

Este estrato arcaico da curiosidade teórica marca a diferença de Tales frente ao mito; determina a possibilidade de nascimento do pensamento filosófico, tal como a tradição da disciplina cuidou de constituir. Esta mesma tradição se ocupa, então, da exegese e hermenêutica da frase de Tales, desde sua compilação até o presente, operando sua passagem da oralidade para a literalidade e constituindo-lhe uma semântica própria. Bruni retoma alguns passos dessa tradição: "Reinterpretando o 'tudo é água' de Tales, Feuerbach diria: 'tudo é homem', ou melhor, 'tudo é espelho do homem', no sentido de que nada da natureza escapa da representação e da ação humanas, da atribuição de sentido e de significado. Não existe a natureza em si, fora das representações e dos atos de atribuição de sentido. E o símbolo da compreensão desta idéia é justamente a água, porque ela é o espelho natural do homem. É com a água que o homem se vê, é com a água que a identidade e a verdade do homem podem ser refletidas, isto é, pensadas objetiva e subjetivamente" (Bruni, 1993, p. 58).

Atento em meio à história dessas interpretações, Bruni tenta discernir um ponto de mira que lhe faculte o movimento e é precisamente aí que vemos sua agudeza: "Depois que a água tornou-se objeto da razão científica, passou a ser um corpo entre os outros, muito importante, é certo, mas sem alma, sem sentido, uma coisa morta" (Bruni, 1993, p. 57). Mas o que haveria de ser a alma da água? Esta é a questão.

No entender de Friedrich Nietzsche, "Tales viu a unidade de tudo o que é: e como ele quis comunicar-se, falou da água!" (Nietzsche, 1988, vol. 1, p. 817). Leiamos o passo com vagar: inicialmente, Tales "viu”; só depois, quando quis "comunicar-se", quando pretendeu "participar" (mittheilen) aos outros o que vira, só então ele fala da água. Portanto, a água surge como uma necessidade expressiva, como estratégia discursiva para falar de algo que, de outro modo, não poderia ser dito. Um comentador do comentário de Nietzsche entende que este "resume admiravelmente o golpe criador do pensador de Mileto, que 'inventa' a arkhé [...] e que a exprime também por uma analogia" (Legrand, 1991, p. 28). Ou seja: o que é visto necessita, para ser expresso, de recursos de uma língua que vive além do mundo dos conceitos (guardemos essa idéia). Voltemos a Nietzsche: "O que é o verso para o poeta, aqui, é para o

filósofo o pensar dialético: é deste que ele lança mão para fixar-se em seu enfeitiçamento, para petrificá-lo. E assim como, para o dramaturgo, palavra e verso são apenas o balbucio em uma língua estranha, para dizer nela o que viveu e viu, assim a expressão daquela intuição filosófica profunda 
${ }^{3}$ Grifo meu.

${ }^{4}$ Cf. Benjamin (1991, vol. I.1, p. 215-218 e 407; vol. II.1, p. 140157 e 204-213; vol. II.3, p. 931-935 e 950960; vol. III, p. 452480 e 673-674; vol. IV.1, p. 9-21; vol. VII.2, p. 789-796). pela dialética e a reflexão científica é, decerto, por um lado, o único meio de comunicar o que foi visto, mas um meio raquítico, no fundo uma transposição metafórica, totalmente infiel, em uma esfera e língua diferentes. Assim Tales viu a unidade de tudo o que é: e como ele quis comunicar-se, falou da água!" (Nietzsche, 1988, vol. 1, p. 817; Nietzsche apud Souza, 1985, p. 12)

Percebemos como o próprio Nietzsche necessita lançar mão da comparação para explanar sobre Tales; o ponto, entretanto, é que para dizer o que viu, Tales precisa da metáfora, da tradução para uma outra língua. Guardemo-las, também, e avancemos mais um instante, ainda sob a condução de Nietzsche: "[...] uma potência estranha, ilógica, a fantasia. Alçado por esta, ele salta adiante, de possibilidade em possibilidade, que por um momento são tomadas por certezas; aqui e ali, ele mesmo apanha as certezas em vôo. Um pressentimento genial as mostra a ele e adivinha de longe que nesse ponto há certezas demonstráveis. Mas, em particular, a fantasia tem o poder de captar e iluminar como um relâmpago as semelhanças: mais tarde, a reflexão vem trazer seus critérios e padrões e procura substituir as semelhanças por igualdades, o que foi visto um-ao-lado-do-outro por causalidades. [...] Ao acolher e discriminar assim o insólito, assombroso, difícil, divino, a filosofia marca o limite que a separa da ciência, do mesmo modo que, ao preferir o inútil, marca o limite que a separa da prudência" (Nietzsche, 1988, vol. 1, p. 814; Nietzsche apud Souza, 1985, p. 11-12)3.

Há dois elementos que é preciso alinhavar: por um lado, a idéia da "transposição a uma outra língua" (donde a "metáfora", o "balbucio") e, por outro, o pensamento que opera por meio das "semelhanças". Trata-se, então, de uma doutrina das semelhanças e o problema que a linguagem e sua traduzibilidade põem a nu; conseqüientemente, trata-se do problema da origem da linguagem, onde vivem as semelhanças e onde as línguas se encontram: uma questão, na verdade, paradisíaca. Walter Benjamin, em enorme comunidade com os pensamentos de Nietzsche apresentados acima, procurou desenvolver exatamente estes problemas no âmbito do que denominou "minha teoria da mimese" . Não é o caso, aqui, de reconstrui-la, mas apenas de chamá-la a mergulhar na frase de Tales. "A essência lingüística do ser humano é portanto que ele dá nome às coisas" (Benjamin, 1991, vol. II.1, p. 143), isto é: tudo é... água. É o homem que denomina aquilo que tudo é. O nome que ele dá a isso é: "água". O nome é conhecimento, dominação da natureza, desmitologização (nomear é dominar, nomear é conhecer, saber é poder). E também origem da abstração e, desse modo, filosofia, pois o esforço para dizer o que, no fundo, o mundo é, é característico da filosofia. "Portanto, o ser humano comunica a sua própria essência espiritual (tanto quanto ela é comunicável) na medida em que ele nomeia todas as outras coisas" (Benjamin, 1991, vol. II.1, p. 143). O que significa que Tales, nomeando a água, exprime a própria essência do humano. Precisamente isto Bruni enzendeu ao ler Feuerbach. Tal capacidade nomeadora do ser humano marca a sua singularidade absoluta, o que vale dizer marca o caráter humano do ser humano. É justamente isto que a frase de Tales afirma. Mas 
por que afirmá-lo nomeando a água? Porque a água é a metamorfose absoluta, é todas as formas.

Água é metamorfose. Opera por semelhança; é por essa razão o elemento mimético por excelência. O “tudo é água” significa, por exemplo, que esse elemento polimorfo e metamorfoseante penetra tudo e se imiscui por entre tudo. Se assim é, ele a tudo se assemelha, é o elemento que opera por meio das semelhanças. Difere, pois, do fogo, que tudo consome, que tudo acolhe em si. A água apaga o fogo.

Como vimos com Nietzsche, há um nexo necessário entre a visão e a nomeação. Naturalmente, um problema fundamental para a filosofia é a apresentação daquilo que se vê, ou seja, a questão que Tales resolve nomeando, e nomeando de um determinado modo dentre muitos possíveis, isto é, mais uma vez, o problema da contingência da linguagem e sua resolução no âmbito da necessidade (pois se a contingência é o que é possível sem ser necessário, determinada nomeação, se não é arbitrária, rompe com a falta da necessidade: para Tales, a "água" precisa ser denominada "água”, ou melhor: o que ele inicialmente viu, na ocasião da nomeação, recebe o nome "água”, e não outro nome qualquer). "Nesta ligação de visão e nomeação, a mudez comunicativa das coisas (dos animais) é referida, internamente, à linguagem de palavras do ser humano, que a acolhe no nome" (Benjamin, 1991, vol. II.1, p. 152). Se assim é, a mudez comunicativa do mundo, que fala ao homem mas não faz uso das palavras, ganha uma voz, uma voz que o tira de seu mutismo radical; o ser humano, compartilhando a prerrogativa divina da nomeação, o redime desse silêncio comunicante.

Precisamos, entretanto, entender a escolha da predicação, que se funda no caráter de metamorfose da água e, como disse, que opera por semelhança. No âmbito da teoria da mimese mencionada, a questão da semelhança foi formulada no caso celeste. Há uma semelhança, portanto continuidade, entre o céu e a terra. No entender de Nietzsche, uma continuidade que se faz mediante antropomorfia: os homens vêem o céu à sua semelhança. Há aqui, pois, uma faculdade capaz de estabelecer semelhanças e reconhecê-las; na medida em que o ser humano vive essa correspondência, há produção de sentido (cf. Gebauer \& Wulf, 1992, p. 374). Nietzsche abordou o problema em um fragmento póstumo do início da década de 1870: "O processo de toda a religião, filosofia e ciência frente ao mundo: ele se inicia com os antropomorfismos os mais grosseiros e não cessa jamais de se refinar. / O ser humano singular contempla até mesmo o sistema celeste como a seu serviço ou em conexão consigo. / Os gregos dissolveram na sua mitologia toda a natureza em grego. Eles consideravam a natureza como que apenas uma mascarada e disfarce das divindadeshomens. Nisto eles eram a contrapartida de todos os realistas. A oposição de verdade e fenômeno estava entranhada neles. As metamorfoses são o que há de específico. / Tales exprimiu isto em sua frase: de que tudo é água" (Nietzsche, 1988, vol. 7, p. 456).

Essa capacidade-faculdade de perceber a continuidade do firmamento com o ser terrestre, capacidade de ler o que está escrito nas 
5 Sobre a "legibilidade", cf. Blumenberg (1999).

6 [...] lá, sobre o próprio papel, não sei qual cintilação dos últimos astros brilhava infinitamente pura no mesmo vazio interconsciente onde, como uma matéria de espécie nova, distribuída em conglomerados, em rastros, em sistemas, coexistente com a Palavra! (N.E.). estrelas - a legibilidade do firmamento, que fala sua linguagem própria e, portanto, participa sua "essência espiritual"' -, surge como antropomorfismo, um caso específico da percepção e reconhecimento de semelhanças.

A afirmação de Tales depende disto tudo: depende da capacidade de ler a linguagem do mar, compreender sua essência e, assim, como humano que é, nomear tudo o que é. Valéry percebeu isto, como lhe ocorria amiúde ao pensar com Mallarmé: “[...] là, sur le papier même, je ne sais quelle scintillation de derniers astres tremblait infiniment pure dans le même vide interconscient où, comme une matière de nouvelle spèce, distribuée en amas, en traînées, en systèmes, coexistant la Parole!" (Valéry apud Blumenberg, 1999 , p. 313) 6 .

O ser humano produz semelhanças, cuja percepção pode ser consciente ou inconsciente. As alterações nesse ato de percepção de semelhanças, assim como no de sua produção, são históricas; disto decorre a diferença frente a Tales e, conseqüentemente, o caráter enigmático de sua afirmação. Na terminologia de Benjamin, as "correspondências mágicas" são muito mais rarefeitas no ambiente do homem moderno, interior e exterior, e disto decorre a extinção - que não se consuma jamais, entretanto - da faculdade mimética, ou melhor, seu retraimento a domínios cada vez mais restritos - como sobretudo a infância, sua terra inviolata.

Naturalmente, o problema que se põe é o da historicidade da percepção humana, algo que foi denominado, certa feita, "educação dos cinco sentidos". A relação com as estrelas, como vimos com Nietzsche, parece ser fundante. No firmamento, nas constelações estelares, na cúpula celeste encontramos um antigo domínio do exercício da faculdade mimética. As danças oferecem disso amplo e variado exemplo (cf. Sachs, 1937, p. 124ss.); como isto está na gênese da concepção benjaminiana, seja-me permitida uma referência: "A dança circular das estrelas, as posições dos planetas em relação às estrelas fixas, a bela ordem e perfeita harmonia em todos seus movimentos - o que é tudo isso senão uma imagem da dança primordial!" (Varro apud Sachs, 1937, p. 124; cf. Woisen, 1992, p. 98). Algo disto já havia sido verbalizado no século II de nossa era, pelo poeta Luciano, em sua obra sobre a dança, na qual se pode ler: "Com a criação do universo, também a dança veio a ser, o que significa a união dos elementos. A dança circular das estrelas, a constelação dos planetas em relação às estrelas fixas, a bela ordem e harmonia em todos os seus movimentos é um espelho da dança original no tempo da criação" (Luciano apud Woisen, 1992, p. 8). Se, como afirmei alhures, os homens fazem os animais dançarem como os homens porque sabem que eles, os homens, dançam como os animais, então algo análogo poderia ser dito acerca das estrelas e do firmamento (cf. Waizbort, 2000; Lonsdale, 1982; Woisen, 1992).

O lugar no cosmos e o sentido da vida, a experiência portanto, tem na faculdade mimética sua principal ancoragem, para os antigos. Mas, como indicou Nietzsche, a capacidade das semelhanças é tributária da fantasia; nesse sentido, ela permanece atuante nos seres humanos. Cabenos, pois, a percepção do relampejar, a sensibilidade da percepção do instante 
em que as correspondências se evidenciam - daí a importância, para a astrologia, do instante do nascimento. A substituição de semelhanças por igualdades, de que falava Nietzsche, é o processo que dá lugar, em parte, ao que Benjamin viria a denominar semelhança insensível: o conceito de semelhança insensível "é, como se compreende por si mesmo, um conceito relativo: ele reza que nós não possuímos em nossa percepção aquilo que, certa vez, tornou possível falar de uma semelhança que subsistia entre uma constelação estelar e um ser humano" (Benjamin, 1991, vol. II.1, p. 207). Se refletirmos sobre isso, podemos entender a frase de Tales como um caso de semelhança insensível, uma via de acesso a uma sensibilidade e percepção históricas que se transformaram no curso que o separa de nós. Este é o fundamento, aliás, da afirmação com que iniciei este texto.

Na teoria da linguagem de Benjamin, a faculdade mimética ocupa posição central. Como ele recusa uma concepção da linguagem baseada na arbitrariedade do signo e no caráter de convenção dos nomes, a faculdade mimética surge como instância articuladora de coisa e nome. Aqui a água como sem forma e com todas as formas aparece, pois, como um elemento significativo como predicado em "tudo é". Ou, dito de outra maneira: a predicação "água” só é possível dado o elemento mimético; a capacidade humana de constituir e reconhecer semelhanças está na base da frase de Tales, o que vale dizer, na origem da filosofia. "Pode-se supor que aquele dom mimético, que outrora foi o fundamento da clarividência, migrou gradativamente, no decorrer de milênios, para a linguagem e para a escrita, nelas produzindo o mais perfeito arquivo da semelhança insensível" (Benjamin, 1991, vol. II.1, p. 209).

Desse modo, o desafio da frase de Tales - tão bem qualificado por Bruni, como vimos - reside no trabalho de decifração dessa história da faculdade mimética, decifração arqueológica de camadas subterrâneas da linguagem, na compreensão da semelhança que aí habita e constitui o núcleo do sentido possível, historicamente possível, do "tudo é água". O passo de Blumenberg, citado no início, em que se falava da apreensão de nexos, é o que Nietzsche e Benjamin denominam percepção de similaridades.

A clarividência de Benjamin não deriva de nos explicar, ainda, o porquê do enigmático, a insistente intransparência da afirmação para nós outros. Isto se deve, precisamente, ao fato de que as semelhanças mostramse naquele relampejar que Nietzsche também percebeu, um "instante crítico" em que a semelhança "relampeja em meio ao fluxo das coisas" (Benjamin, 1991, vol. II.1, p. 210, 209).

Dizem-nos os relatos que Tales era um viajante, tendo percorrido várias paragens da Ásia Menor. Saberia o explorador aventureiro que toda terra incógnita é cercada de água? O habitante do arquipélago é um viajante, um nauta e, potencialmente ao menos, um náufrago. "O porto não é uma alternativa 
ao naufrágio, ele é o lugar da felicidade de vida perdida" (Blumenberg, 1997,

p. 39). É preciso que nos aventuremos. Lancemo-nos ao mar, deixemo-nos envolver pelas águas, ondas, correntes, “[...] deixando-se levar ora nesta ora naquela direção, com um movimento qualquer dos braços. Envolto pelo elemento líquido, o corpo solta-se do chão, os pés já não pisam, as pernas não andam. É quase uma dança sem rigor: mergulhos incompletos, meias-voltas, algo como um fantoche movido displicentemente, sem a menor intenção de suscitar a imagem de um movimento regular. Sensação de liberdade, não sentimos mais o peso e a gravidade. Sensação de amparo, de um doce abraço permanente - a carícia do mar envolve o corpo todo, cintilando e espumando, oferecendo a resistência justa, o calor no ponto exato" (Bruni, 1993, p. 63-64).

A felicidade mostra-se, aqui, em sua constelação, amparada pela liberdade, pelo vagar livre, pela fantasia que fantasia livre, solta, saltitante. A felicidade é contígua ao atirar-se, ao desprender-se. "Talvez a verdadeira sociedade se farte do desenvolvimento e deixe, por pura liberdade, possibilidades sem utilizar, ao invés de se precipitar, por uma louca compulsão, rumo a estrelas distantes. Uma humanidade que não conheça mais a necessidade começará a compreender um pouco o caráter ilusório e vão de todos os empreendimentos realizados até então para se escapar da necessidade e que, com a riqueza, reproduziram a necessidade numa escala ampliada. Até mesmo o prazer seria por isso afetado, visto que seu esquema atual é inseparável da industriosidade, do planejamento, intenção de impor a sua vontade, da sujeição. Rien faire comme une bête ${ }^{7}$, flutuar na água, olhando pacificamente para o céu, 'ser, e mais nada, sem nenhuma outra determinação nem realização', eis o que poderia ocupar o lugar do processo, do fazer, do realizar, e, assim, cumprir verdadeiramente a promessa da lógica dialética, de desembocar em sua origem" (Adorno, 1993, \# 100).

Na origem, a água, "tudo é água". Seria ela a redenção, tal como Bruni nos diz, retomando Feuerbach? Seria o contato com a água aquele contato sem violência e sem arbítrio de que falava Adorno e de que dependeria o pensamento? (cf. Adorno, 1993, \# 153).

Em um passo já citado, Nietzsche marcava o lugar da filosofia e sua preferência pelo inútil, sua imprudência. No prefácio que escreveu para suas Valses nobles et sentimentales, Maurice Ravel refere-se ao "prazer delicioso e sempre novo de uma ocupação inútil". Entretanto, seria um erro pensar que essa famosa dedicatória pudesse ser explicada pela idéia da arte pela arte. Antes, trata-se da recusa em aceitar que o prazer deva estar submetido à utilidade - exatamente o que Benjamin assinalava, tanto a respeito da relação do colecionador com seus objetos, como na caracterização do flâneur como o "ocioso que sonha" (Benjamin, 1991, vol. V.1, p. 525; vol. V.2, p. 961-970). Esta mesma é uma caracterização que remete às crianças e à infância: quem pode desfrutar tanto da ociosidade como as crianças, quem pode sonhar tão livremente? Na recusa sempre constante da utilidade, Ravel permanece uma criança, brincando pelo prazer de brincar. 
A brincadeira é a "escola" da faculdade mimética; os comportamentos miméticos da criança marcam as "forças miméticas" como constituintes do processo de comunicação do ser humano em seu mundo da vida. A mimese é um mecanismo essencial na constituição de um mundo de vida dos seres humanos, assim como mecanismo fundamental na constituição de um self (cf. Benjamin, 1991, vol. IV.1, p. 235-304; vol. VII.1, p. 385-433; Gebauer \& Wulf, 1992).

Não estamos longe demais da interpretação de um psicanalista; assim a formula Otto Rank: "Trata-se de uma verdadeira descoberta, da supressão de um véu, ou, como diríamos, da supressão de um recalque que impedira até então que se reconhecesse na água a fonte e a origem de toda vida, e isso precisamente porque o próprio homem sai de uma fonte líquida, representada pelas águas amnióticas" (Rank apud Legrand, 1991, p. 31). O útero materno não é aquele ambiente que Bruni descrevera como "envolvendo o corpo todo", oferecendo o "calor no ponto exato"? O mar como mãe leva-nos, em seu fluxo ondular, ao oceano homérico, "Okéanos", "ilimitado" (cf. Legrand, 1991, p. 28). Ademais, Rank permite-nos a aproximação a uma idéia de Lucrécio: “[...] aqui o nascimento do ser humano é visto como naufrágio. A natureza joga a criança para fora do corpo da mãe, para a orla da luz (in luminis oras), assim como o nauta é atirado à terra pelas ondas enfurecidas. Já o início, e não só o curso e o fim da vida, está sob a metáfora do naufrágio" (Blumenberg, 1997, p. 33).

Na verdade, Adorno aproxima-se de uma página de Benjamin, em que se afirmara que a dialética habitava a origem. A origem relaciona-se com o que foi e o que será, com o que já não é e com o que virá, com o que se concretizou e com o que requer acabamento (cf. Benjamin, 1991, vol. I.1, p. 226; vol. IV.1, p. 19). Nesse sentido, a afirmação de Tales é tanto restauração como abertura para o desconhecido, navegação rumo à terra incógnita.

Desembocar na origem. Origem (arkhé) que se apresenta como sendo $a$ questão filosófica (cf. Legrand, 1991, p. 30-31); que não se confunde com o mito - um tema que Nietzsche, em suas anotações, não se cansa de repetir: Tales como o anti-mito6. "[...] A inconceptualidade não é congruente com a visibilidade. Não é correto que o mito teria sido a pátria da visão anterior à odisséia da abstração. A afirmação mítica de que tudo seria rodeado pelo oceano e origina-se dele não é, no final das contas, mais visível do que aquela segundo a qual tudo se origina da água. Ambas têm suas dificuldades em serem exequiíveis como instruções para a nossa capacidade de representação. Não obstante, essa 'tradução' de Tales de Mileto é cheia de conseqüências, pois nela aparece uma afirmação que quer ser tomada como resposta a uma pergunta. Isto é completamente estranho ao mito [...]" (Blumenberg, 1997, p. 96). O caráter de desmitologização no nascimento do conhecimento faz uso da capacidade de abstração; na frase de Tales, a abstração apareceria como uma "capacidade do espírito lingüístico"7. Por outro lado, como se viu em Blumenberg, Benjamin e Nietzsche, há aqui uma "tradução". Esta é o caminho para uma linguagem mais perfeita, capaz de 
desembocar na origem. Traduzir em uma língua diferente é a possibilidade de redenção da essência, que já se acha ocultada pela história da faculdade mimética, como diria Benjamin. Assim, a semelhança insensível torna-se perceptível.

A teoria da mimese que acompanhamos vê-se forçada, aqui, a incorporar em si uma teoria da tradução. "Como a palavra muda estaca para trás tão infinitamente na existência das coisas, sob a palavra nomeadora no conhecimento do ser humano; como esta, por sua vez, estaca sob a palavra criadora de Deus, assim está dado o fundamento para a multiplicidade das linguagens humanas. A linguagem das coisas pode penetrar $n a$ linguagem do conhecimento e na linguagem do nome apenas na tradução [...]. A linguagem paradisíaca do ser humano só pode ter sido a linguagem perfeita do conhecimento; enquanto que, mais tarde, uma vez mais todo conhecimento diferencia-se infinitamente na pluralidade da linguagem [...]" (Benjamin, 1991, vol. II.1, p. 152). A linguagem de Tales aparece, nomeadora, em meio a essa pluralidade; ela se alça acima da linguagem das coisas, linguagem nomeadora que é, na busca do conhecimento. O processo de tradução, entretanto, é infinito; é ele que se põe como problema na(s) nossa(s) leitura(s) de Tales. "A linguagem de um ser é o medium na qual ele comunica sua essência espiritual. A corrente ininterrupta dessa comunicação corre por toda a natureza do que existe de mais inferior até o ser humano e do ser humano até Deus" (Benjamin, 1991, vol. II.1, p. 157). A comunicação perfeita é a comunicação do paraíso (cf. Waizbort, 1999), o estado de paz. Mas isto só assume a forma da clareza absoluta na linguagem de Deus, que funde toda a semelhança sem que, com isso, recaia em uma lógica da identidade. O nexo com a lógica dialética radica aqui, na não-identidade do particular e conceito (cf. Adorno, 1983). O conhecimento humano, por essa razão, permanece sempre atiçado por alguma obscuridade: "[...] o conhecimento se dá numa rede onde se entrelaçam préjuízos, intuições, inervações, autocorreções, antecipações e exageros, em poucaspalavras, na experiência, que é densa, fundada, mas de modo algum transparente em todos os seus pontos" (Adorno, 1993, \# 50). Ele é como água.

"Do oceano, que circunscreve a margem do mundo habitável, vêm os monstros míticos que estão o mais afastados possível das formas da natureza com que estamos familiarizados e que parecem nada mais saber acerca do mundo enquanto cosmos. Dentre as lugubridades de tal espécie pertence também o fato de que o terremoto - dentre os fenômenos naturais sempre o mais aterrorizante - pertence à competência mítica da divindade do mar, Poseidon. Na declaração semi-mítica do primeiro dos filósofos jônicos da natureza, Tales de Mileto, o terremoto é comparado com o tremor do barco sobre o mar - e isto não apenas metaforicamente, pois para ele a terra firme flutua sobre o oceano do mundo. O protofilósofo lança com isso também a mais antiga ponte para a compreensão do paradoxo peculiar [...] 
de que o ser humano, enquanto ser da terra firme, apresenta contudo o de seu estado no mundo preferencialmente nas imaginações da jornada no mar" (Blumenberg, 1997, p. 9-10).

Talvez se possa, até mesmo, especular acerca do reduzido e fragmentário do espólio de Tales, pois que, uma vez tendo dito que tudo é água, nada mais restou, exceto o silêncio. Então, envolto em silêncio, ele submergiu no mar, lentamente.

Recebido para publicação em outubro/2000

WAIZBORT, Leopoldo. Gloss - bastard speculation about water. Tempo Social; Rev. Sociol. USP, S. Paulo, 12(2): 37-48, November 2000.

ABSTRACT: I dwell upon an article previously published in Tempo Social, by José Carlos Bruni, in the hope of "understanding water as water" and the implications of such an edeavour.

\section{REFERÊNCIAS BIBLIOGRÁFICAS}

ADORNO, Theodor W. (1983) Negative Dialektik. Frankfurt/M, Suhrkamp.

. (1993) Mínima moralia. Reflexões a partir da vida danificada. São Paulo, Ática.

BENJAMIN, Walter. (1991) Gesammelte Schriften. Frankfurt/M, Suhrkamp.

BLUMENBERG, Hans. (1987) Die Sorge geht über den Fluss. Frankfurt/ M, Suhrkamp.

. (1997) Schiffbruch mit Zuschauer. Paradigma einer Daseinsmetapher. Frankfurt/M, Suhrkamp.

. (1999) Die Lesbarkeit der Welt. Frankfurt/M, Suhrkamp.

BORGES, Jorge Luis. (1997) Obras completas en colaboración. Buenos Aires, Emecé.

BRUNI, José Carlos. (1993) A água e a vida. Tempo social, São Paulo, 5(1-2): 53-65.

ELIOT, T. S., DICKINSON, Emily \& DEPESTRE, René. (1992) Seleção. Tradução Idelma Ribeiro de Faria. São Paulo, Hucitec.

GEBAUER, Gunter \& Wulf, Christoph. (1992) Mimesis. Kultur-KunstGesellschaft. Reinbeck, Rowohlt.

LEGRAND, Gérard. (1991) Os pré-socráticos. Rio de Janeiro, Zahar. 
LONSDALE, Steven. (1982) Animals and the origins of dance. New York, Thames and Hudson.

NIETZSCHE, Friedrich. (1988) Kritische Studienausgabe. München, DTV.

SACHS, Curt. (1937) World History of Dance. New York, W.W. Norton.

SOUZA, José C. (org.) (1985) Os pré-socráticos. Fragmentos, doxografia e comentários. São Paulo, Abril.

WAIZBORT, Leopoldo. (1999) Paraíso. Texto inédito. . (2000) A dança dos animais. Texto inédito.

WOISEN, Maria-Gabrielle. (1992) Sacred dance. Encounter with the Gods. New York, Thames and Hudson. 